\title{
High Amplification Rates from the Association of Two Enzymes Confined within a Nanometric Layer Immobilized on an Electrode. Modeling and Illustrating Example.
}

\author{
Benoît Limoges*, Francois Mavré, Damien Marchal, and Jean-Michel Savéant* \\ Laboratoire d'Electrochimie Moléculaire, Université de Paris 7 - Denis Diderot, 2 place Jussieu, 75251 Paris Cedex 05, France.
}

\section{Experimental \\ Chemicals}

NADH (Sigma), p-aminophenol (Prolabo), $p$-aminophenyl- $\beta$ D-galactopyranoside (PAPG) (Sigma), bovine serum albumine (BSA) (Sigma), magnesium chloride (Sigma), neutravidin (Pierce), biotinamidohexanoic acid 3-sulfo-Nhydroxysuccinimide ester sodium salt (Pierce) were used as received. Ferrocenyl methanol (Aldrich) was recrystallized twice from toluene and cyclohexane. Lyophilised Diaphorase from Bacillus stearothermophilus (E.C. 1.6.99.-) was purchased from Unitika (Japan) and lyophilised $\beta$-galactosidase ( $\beta$-Gal) from Escherichia Coli was obtained from SIGMA. The $0.1 \mathrm{M}$ Tris buffer of $\mathrm{pH} 8.5$ was prepared from $4.42 \mathrm{~g} \mathrm{~L}^{-1}$ Trizma base (Sigma) and $8.72 \mathrm{~g} \mathrm{~L}^{-1}$ Trizma, $\mathrm{HCl}$ (Sigma). The phosphate buffer $\left(\mathrm{PB}, \mathrm{pH}\right.$ 7) was prepared from $6.08 \mathrm{~g} \mathrm{~L}^{-1}$ $\mathrm{NaH}_{2} \mathrm{PO}_{4}$ and $21.84 \mathrm{~g} \mathrm{~L}^{-1} \mathrm{Na}_{2} \mathrm{HPO}_{4}, 12 \mathrm{H}_{2} \mathrm{O}$. All aqueous solutions were prepared with water purified by a Milli-Q water purification system from Millipore.

\section{Biotinylation of enzymes}

Diaphorase was biotinylated as previously described. ${ }^{4} \beta$ galactosidase was biotinylated as follows: $2.26 \mathrm{mg}$ of lyophilized $\beta$-galactosidase dissolved into $1 \mathrm{~mL}$ of $0.1 \mathrm{M} \mathrm{PB}$ $(\mathrm{pH} 7)$ was mixed with $52 \mu \mathrm{L}$ of a biotinamidohexanoic acid 3sulfo-N-hydroxysuccinimide ester solution $(2.2 \mathrm{mg}$ in $400 \mu \mathrm{L}$ of Milli-Q water). The mixture was left at room temperature for $3 \mathrm{hrs}$ and then centrifuged (8000 $\mathrm{g}$ for $20 \mathrm{~min})$ through a microconcentrator membrane (10000 MW cutoff, Nanosep, Pall), followed by washing four times with PB $(4 \times 0.5 \mathrm{~mL})$. The concentrated biotinylated $\beta$-galactosidase was finally recovered in $400 \mu \mathrm{L} \mathrm{PB}$ and its concentration determined spectrophotometrically using $\mathrm{E}^{1 \%}=20.9$ (absorbance of a $1 \%$ in weight solution of protein at $280 \mathrm{~nm}){ }^{\mathrm{S} 1}$

\section{Enzymes kinetics.}

The kinetics of biotinylated diaphorase immobilized on a carbon electrode by attachment to a neutravidin monolayer has been previously described. ${ }^{4}$ The homogeneous kinetics of the reaction of biotinylated $\beta$-galactosidase with $p$-aminophenyl- $\beta$ D-galacto-pyranoside (PAPG) substrate has been determined from the amperometric response recorded at a glassy carbon electrode immersed in a solution containing $10 \mathrm{nM} \beta$ galactosidase and a range of PAPG concentrations from 50 to $1000 \mu \mathrm{M}$ in Tris buffer containing $0.2 \mathrm{~g} \mathrm{~L}^{-1}$ of $\mathrm{MgCl}_{2}$. The electrode potential was stepped from 0 to $0.3 \mathrm{~V}$ vs. SCE, a positive enough value for the product of the enzymatic reaction (PAP) to be completely oxidized. Under such a conditions, the time-dependent current response, $d i / d t$, is proportional to the rate at which PAP is produced in the bulk of the solution and is thus directly related to the rate of the enzymatic reaction (equation S1).

$$
\frac{d i}{d t}=2 F S \frac{\mathrm{D}_{Q}}{\delta}\left(\frac{d[\mathrm{PAP}]}{d t}\right)=2 F S \frac{\mathrm{D}_{Q}}{\delta} V
$$

where $V$ is the rate of the enzymatic reaction. At time $t=0$, the initial rate, $V_{0}$, is related to the enzyme kinetics according to equation (equation $\mathrm{S} 2$ )

$$
V_{0}=\left(\frac{d[\mathrm{PAP}]}{d t}\right)_{t=0}=k_{1,2} C_{E}^{0} \frac{[\mathrm{PAPG}]_{t=0}}{K_{1, M}+[\mathrm{PAPG}]_{t=0}}
$$

$C_{E}^{0}$ is the total enzyme concentration in solution. Fitting the variation of the initial rate, $V_{0}$, with the initial substrate concentration, $[\mathrm{PAPG}]_{t=0}$, with equation (equation S2), leads to: $k_{1,2}=12 \mathrm{~s}^{-1}$ and $K_{1, \mathrm{M}}=140 \mu \mathrm{M}$.

\section{Building of the bienzymatic layer on carbon electrodes}

All experiments were performed at room temperature. A drop of $6 \mu \mathrm{L}$ of $1 \mathrm{mg} \mathrm{mL}^{-1}$ neutravidin in $\mathrm{PB}$ was deposited on the glassy carbon electrode and incubated for $2 \mathrm{hrs}$ in a watersaturated atmosphere. The electrode surface was next thoroughly rinsed with $\mathrm{PB}$ and immersed $15 \mathrm{mn}$ in a buffer solution containing $0.1 \%$ BSA. The biotinylated $\beta$ galactosidase was deposited by dipping the electrode for $2 \mathrm{hrs}$ in either $0,0.1,1$ or $100 \mathrm{nM}$ biotinylated $\beta$-galactosidase diluted in Tris. After rinsing with Tris, the electrodes were immersed for $15 \mathrm{~min}$ in a $0.1 \mu \mathrm{mol} \mathrm{L} \mathrm{L}^{-1}$ neutravidin in Tris (this step may be skipped for electrodes previously incubated in $\leq 1$ $\mathrm{nM}$ biotinylated $\beta$-galactosidase solution) and next incubated for $30 \mathrm{mn}$ in $0.1 \mu \mathrm{M}$ biotinylated diaphorase in Tris. The electrodes were stored in $\mathrm{PB}$ at $4^{\circ} \mathrm{C}$ and used within one hour after the last incubation.

\section{Instrumentation}

Cyclic voltammetry and chronoamperometry measurements were performed with an AUTOLAB potentiostat, PGSTAT 12 (Ecochemie), interfaced to PC computer (GPES software). The water-jacketed electrochemical cell was maintained at $20 \pm 0.5$ ${ }^{\circ} \mathrm{C}$ with a circulating water bath. All measurements were carried out in a $0.1 \mathrm{M}$ Tris buffer solution $(\mathrm{pH} 8.5)$ containing $0.2 \mathrm{~g} \mathrm{~L}^{-1}$ of $\mathrm{MgCl}_{2}$ using a saturated calomel electrode (SCE) as reference electrode, a platinum wire as counter-electrode and a $3 \mathrm{~mm}$-diameter glassy carbon disk as working electrode.

\section{Procedures}

The chronoamperometric experiments were carried out as follows. The potential of the enzyme-modified electrode immersed in a Tris buffer was stepped from 0 to $0.3 \mathrm{~V}$ vs. SCE and, after decrease and stabilization of the initial current, a first aliquot $(50 \mu \mathrm{L})$ of a concentrated PAPG solution $(50 \mathrm{mM})$ was added. After de novo stabilization of the current, a second aliquot $(100 \mu \mathrm{L})$ of a concentrated NADH solution $(100 \mathrm{mM})$ was added (Figure S1). At the end of the chronoamperometric
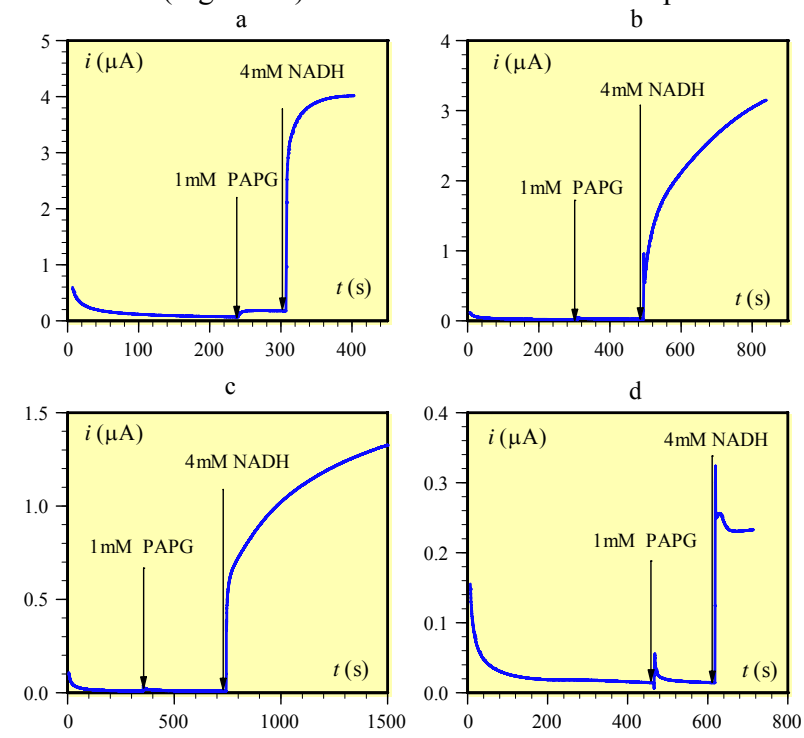

Figure S1. Chronoamperometric responses recorded at bienzymecoated electrodes incubated initially in different solutions of biotinylated $\beta$-galactosidase, i.e.: (a) 100 , (b) 1 , (c) 0.1 , and (d) $0 \mathrm{nM}$. 
measurement, $50 \mu \mathrm{L}$ of a $1 \mathrm{mM}$ ferrocene methanol solution was introduced and a cyclic voltammogram recorded (Figure S2). The surface concentration of immobilized diaphorase was then derived from the plateau currents, using the rate constant values previously determined. ${ }^{4}$

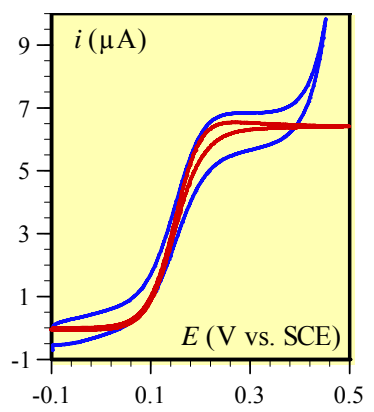

Figure S2. Blue line: cyclic voltammogram recorded at the end of the chronoamperogram (b) of Figure S1 and after the addition of $20 \mu \mathrm{M}$ $\mathrm{FcMeOH}$ to the solution- Red line: simulated voltammogram using $k_{2}=$ $2 \times 10^{6} \mathrm{M}^{-1} \mathrm{~s}^{-1}, k_{2,2}=700 \mathrm{~s}^{-1}, k_{3}=3.5 \times 10^{8} \mathrm{M}^{-1} \mathrm{~s}^{-1}, \Gamma_{2}^{0}=0.75 \mathrm{pM} \mathrm{cm}^{-2}$, $E_{\mathrm{FcMeOH}}^{0}=0.195 \mathrm{~V} v \mathrm{~s}$. SCE, $k_{\mathrm{s}}=0.2 \mathrm{~cm} \mathrm{~s}^{-1}$ (standard rate constant for the oxidation of $\mathrm{FcMeOH}), D_{\mathrm{FcMeOH}}=6.7 \times 10^{-6} \mathrm{~cm}^{2} \mathrm{~s}^{-1}$.

\section{Derivation of the theoretical relationships}

In the absence of the auxiliary enzyme, derivation of equation (1) is as follows. We consider a steady-state situation and thus a steady-state current, with a diffusion-convection layer of thickness $\delta$, defined by the natural convection that takes place in the solution. This means that the concentration gradients of the diffusing species, $\mathrm{S}$ and $\mathrm{Q}$, are linear in throughout the diffusion-convection layer:

$$
-\left(\frac{d[\mathrm{Q}]}{d x}\right)_{X=0}=\frac{[\mathrm{Q}]_{X=0}}{\delta}
$$

where $C_{\mathrm{S}}^{0}$ is the bulk concentration of the substrate $\mathrm{S}$. The potential of the electrode is set at a negative enough value (for a reduction, positive for an oxidation) for the concentration of $\mathrm{P}$ to be nil at the electrode surface. All P produced is thus converted immediately into $\mathrm{Q}$ that diffuses out to the solution. The enzyme surface concentrations are assumed to obey the steady-state condition, and therefore, the current, $i_{1}$, is given by:

$$
\frac{i_{1}}{F S}=-D_{\mathrm{Q}}\left(\frac{d[\mathrm{Q}]}{d x}\right)_{X=0}=D_{\mathrm{S}}\left(\frac{d[\mathrm{~S}]}{d x}\right)_{X=0}
$$

coupling with the enzymatic reaction leads to:

$$
D_{\mathrm{S}}\left(\frac{d[\mathrm{~S}]}{d x}\right)_{x=0}=k_{1,1}([\mathrm{~S}])_{x=0} \Gamma_{\mathrm{E}_{1}}-k_{1,-1} \Gamma_{\mathrm{E}_{1} \mathrm{~S}}=k_{1,2} \Gamma_{\mathrm{E}_{1} \mathrm{~S}}
$$

$\Gamma_{\mathrm{E}_{1}}, \Gamma_{\mathrm{E}_{1} \mathrm{~S}}$ are the surface concentrations of the two forms of the enzyme, $D_{\mathrm{S}}$ and $D_{\mathrm{Q}}$ the diffusion coefficient of the subscript species. From the steady-state conditions for $\mathrm{E}_{1} \mathrm{~S}$

$\Gamma_{\mathrm{E}_{1} \mathrm{~S}}=\Gamma_{\mathrm{E}_{1}} \frac{[\mathrm{S}]_{X=0}}{K_{1, M}} \quad\left(K_{1, \mathrm{M}}=\left(k_{1,-1}+k_{1,2}\right) / k_{1,1}\right)$

and from:

$\Gamma_{\mathrm{E}_{1}}+\Gamma_{\mathrm{E}_{1} \mathrm{~S}}=\Gamma_{1}^{0}$

( $\Gamma_{1}^{0}$ : total surface concentration of the first enzyme) one obtains:

$$
\Gamma_{\mathrm{E}_{1}}=\Gamma_{1}^{0} \frac{K_{1, M}}{K_{1, M}+[\mathrm{S}]_{X=0}}
$$

$$
\Gamma_{\mathrm{E}_{1} \mathrm{~S}}=\Gamma_{1}^{0} \frac{[\mathrm{S}]_{X=0}}{K_{1, M}+[\mathrm{S}]_{X=0}}
$$

Thus leading to equation (1).

In the presence of the second enzyme, we derive from the fluxes equations (2) and (3) that:

$$
-D_{\mathrm{Q}}\left(\frac{d[\mathrm{Q}]}{d x}\right)_{x=0}=k_{1,2} \Gamma_{\mathrm{E}_{1} \mathrm{~S}}
$$

and thus from equation (S9):

$$
-D_{\mathrm{Q}}\left(\frac{d[\mathrm{Q}]}{d x}\right)_{X=0}=k_{1,2} \Gamma_{1}^{0} \frac{[\mathrm{S}]_{X=0}}{K_{1, M}+[\mathrm{S}]_{X=0}}
$$

Taking equation (S3) into account, leads to the following expression of the concentration of $\mathrm{Q}$ at the electrode surface.

$$
[\mathrm{Q}]_{X=0}=k_{1,2} \Gamma_{1}^{0} \frac{[\mathrm{S}]_{X=0}}{K_{1, M}+[\mathrm{S}]_{X=0}} \frac{\delta}{D_{\mathrm{Q}}}
$$

For the second enzyme, the steady-state conditions write:

$$
\Gamma_{\mathrm{E}_{2}}=\Gamma_{\mathrm{E}_{2} \mathrm{~S}} \frac{K_{2, M}}{C_{\mathrm{R}}^{0}}, k_{2,2} \Gamma_{\mathrm{E}_{2} \mathrm{R}}=k_{3}[\mathrm{Q}]_{X=0} \Gamma_{\mathrm{E}_{3}}
$$

We may assume that the concentration of $\mathrm{R}$ is large enough for:

$$
\Gamma_{\mathrm{E}_{2}}=\Gamma_{\mathrm{E}_{2} \mathrm{~S}} \frac{K_{2, M}}{C_{\mathrm{R}}^{0}} \cong 0
$$

Thus:

$$
\Gamma_{\mathrm{E}_{2} \mathrm{R}}+\Gamma_{\mathrm{E}_{3}} \cong \Gamma_{2}^{0}
$$

where $\Gamma_{2}^{0}$ is the surface concentration of the second enzyme. It follows from eqns (S13) and (S15) that:

$$
\Gamma_{\mathrm{E}_{3}}=\frac{\Gamma_{2}^{0}}{1+\frac{k_{3}([\mathrm{Q}])_{X=0}}{k_{2,2}}}
$$

i.e.,

$$
k_{3}([\mathrm{Q}])_{x=0} \Gamma_{\mathrm{E}_{3}}=\frac{\Gamma_{2}^{0}}{\frac{1}{k_{3}([\mathrm{Q}])_{x=0}}+\frac{1}{k_{2,2}}}
$$

Combination of equations (S17), (3) and (1) leads to

$$
\frac{i}{F S}=\frac{i_{1}}{F S}+\frac{k_{3} \Gamma_{2}^{0} \frac{\delta}{D_{\mathrm{Q}}} \frac{i_{1}}{F S}}{1+\frac{k_{3}}{k_{2,2}} \frac{\delta}{D_{\mathrm{Q}}} \frac{i_{1}}{F S}}
$$

and finally to equation (4).

REFERENCES AND NOTES

S1. Craven, G. R.; Steers, E.; Anfinsen, C. B. J. Biol. Chem. 1965, 240, 2468. 